\title{
Fiziksel Etkileşimli Oyun Tasarımı Sürecinde Katılımcı Görüşlerinin Belirlenmesi
}

\author{
Yavuz İNAL ${ }^{1}$, Kürşat ÇAĞILTAY ${ }^{2}$ \\ ${ }^{1}$ TÜBİTAK - BİLGEM - Yazılım Teknolojileri Araştırma Enstitüsü (YTE) \\ ${ }^{2}$ Orta Doğu Teknik Üniversitesi, Eğitim Fakültesi, Bilgisayar ve Öğretim Teknolojileri Eğitimi Bölümü \\ yavuz.inal@tubitak.gov.tr, kursat@metu.edu.tr \\ (Geliş/Received: 20.06.2015; Kabul/Accepted: 11.08.2015)
}

DOI: $10.17671 / \mathrm{btd} .80651$

\begin{abstract}
$\ddot{O}_{z}$ et - Bu çalışma fiziksel etkileşime dayanan bilgisayar oyunlarının tasarım aşamasında katılımcı görüşlerinin belirlenmesini ve buna yönelik dikkat edilmesi gereken konuların ortaya konulmasını amaçlamaktadır. Çalışma kapsamında 4 farklı fiziksel etkileşimli (fare ve klavyeye bağlı olmadan bir kamera aracılığıyla oynanabilen) bilgisayar oyunu geliştirilmiştir. Oyunların 2 tanesi hareket kontrollü etkileşim tasarımına sahip iken, diğer oyunlar hareket yönlendirmeli etkileşim tasarımına sahiptir. Çalışmada 5 erkek ve $5 \mathrm{kız}$ olmak üzere 10 öğrenci katılımcı olarak yer almıştır. Çalışma sonucunda elde edilen bulgulara göre, fiziksel etkileşime dayanan oyunlarda kamera ekranının oyun arayüzündeki tasarımının önemli olduğu görülmüştür. Oyun ortamı ile doğrudan etkileşime geçildiği oyunlarda katılımcıların motivasyonu ve oyuna karşı ilgilerinin daha yüksek olduğu belirlenmiştir. Bunun yanında fiziksel efor gerektiren bu tür oyunlarda oyun süreleri ve oyunculardan beklenen fiziksel hareketlerin de dikkatli belirlenmesi gereği ortaya çıkmıştır.
\end{abstract}

Anahtar Kelimeler - oyun tasarımı, fiziksel etkileşimli oyunlar, hareket kontrollü etkileşim tasarım, hareket yönlendirmeli etkileşim tasarımı, insan bilgisayar etkileşimi

\section{Physically Interactive Game Design Process: Understanding Players' Views}

\begin{abstract}
The present study aims to investigate participants' views on design processes of physically interactive computer games and critical points to be considered in these processes. For this purpose, four different physically interactive computer games (connecting on a camera and played without using mouse and keyboard) were developed. Two of these games have motion controlled interaction design, while others have motion driven interaction design. A total of ten students, including 5 boys and 5 girls participated to the study. The study findings revealed that design of camera screen in the game environment is very crucial for motion controlled interactive games. It was observed that participants' motivation and interest to the games are getting higher when they interact with the game environment directly. Moreover, the results also suggested that game duration and the amount of physical movements required by the game should be considered carefully in the design process of physically interactive games.
\end{abstract}

Keywords - game design, physically interactive games, motion-controlled interaction design, motion-driven interaction design, human-computer interaction

\section{GİRIŞ (INTRODUCTION)}

Gelişen teknolojilerle birlikte bilgisayar oyunlarının sahip oldukları özellikler değişime uğramakta, insanların oyun oynama yöntemleri ve alışkanlıkları bu değişimden etkilenmektedir. 30 yıldan fazla bir süredir insan hayatının temel eğlence ve boş zaman değerlendirme araçlarından olan oyunlar modern toplumların popüler 
kültürlerinin vazgeçilmez unsurlarından biri haline gelmektedirler [1-2]. Bunun sonucu olarak ise, oyunların eğitim amaçlı kullanımlarından iş dünyasına, askeri simülasyondan sağlık alanındaki uygulamalarına kadar pek çok farklı sektörde kullanıldıkları görülmektedir.

Oyunlar özellikle çocuklar tarafından yoğun olarak tercih edilmektedir. Günümüzde artık pek çok çocuk erken yaşlarda bilgisayar oyunları ile tanışmaktadır [3] Çocukların oyunlar karşısında geçirdikleri zamanların artışı ile birlikte, bilgisayar teknolojilerinin çocukların yaşamlarını nasıl etkilediklerinin de sorgulanması gereği ortaya çıkmaktadır [4]. Fiziksel etkileşimli oyunlar bilgisayar oyunlarının son yıllarda ortaya çıkan yeni türlerinden birisidir. Oyunlarla insanların arasındaki etkileşimin farklı bir biçimde uygulandığı fiziksel etkileşimli oyunlarda, oyuncular oyun ortamında vücut hareketlerini kullanarak ve dolayısıyla fiziksel güç harcayarak oyunu oynamaktadırlar [5].

Fiziksel etkileşimli oyunlarda oyuncular fare veya klavye gibi aygıtları ana gereksinim olarak kullanmadıklarından dolayı, bilinen klasik oyunlardan oldukça farklı bir etkileşim geliştirmektedirler [5]. Bu tür oyunların gelişimi ile birlikte özellikle çocukların günlük aktivitelerinde gerçekleştirdikleri sadece bir monitör karşısında uzun zamanlar geçirmesi [6] durumuna önemli bir alternatif ortaya konulmaktadır. Fiziksel etkileşimli oyunlar, oyun ortamı ile dış dünya arasında önemli bir köprü görevi üstlenecek potansiyele sahiptirler. Zira bu oyunları oynamak için oyuncuların içerisinde bulundukları fiziksel ortamları kendi oyun alanları olarak kullanmaları, oyunun temel gereksinimlerinden olmaktadır. Fiziksel etkileşimli oyun tasarımı oldukça yeni bir alandır [7]. Bu alanda yapılan oyun tasarımı ve geliştirilmesi çalışmaları son yıllarda yeni yeni ortaya çıkmakta, araştırmacılar oyunların hem tasarım süreçlerini hem de oyuncuların oyun oynama örneklemlerini ortaya koymaya çalışmaktadırlar. Örneğin, fiziksel etkileşimli oyunları kullanarak Tayvan'daki bir ilkokul öğrencilerinin yerel lehçelerini geliştirmeyi amaçlayan bir araştırmada [8] iki fiziksel etkileşime sahip oyun geliştirilmiştir. Çalışma sonunda öğretmenlerin ve öğrencilerin bu tür oyunların eğitim ortamlarında kullanımlarının faydalı olacağına dair ortak görüş bildirdikleri ve oyun esnasında öğrencilerin motivasyonlarının oldukça yüksek olduğu belirlenmiştir.

QuiQui’s Giant Bounce isimli diğer bir fiziksel etkileşime sahip oyun ile çocukların oyun esnasındaki fiziksel hareketlerinin analizi araştırılmış ve bu sonuçların oyun tasarımını nasıl etkileyeceğinin belirlenmesi amaçlanmıştır [9]. Çalışmada bu tür oyunlardaki kontrolün oyuncular için sezgisel olması ve oyunlarda ihtiyaç duyulan fiziksel gereksinimin hedef kitle için uygun olacak şekilde tasarlanması gereği ortaya konulmuştur. Çalışma sonucunda fiziksel etkileşimli oyunlarda ihtiyaç duyulan temel gereksinimler "sağlamlık", "cevaplanabilirlik", "sezgisellik" ve "fiziksel uygunluk" olarak belirlenmiştir.
Bunun yanında fiziksel etkileşimli oyunları oynamak için, oyun oynayan kişilerin aşağıdaki bazı temel motor ve bilişsel gereksinimlere sahip olmaları gerektiği belirtilmiştir [10];

- Lokomotor beceriler (A noktasından B noktasına yapılan vücut hareketi) ile oyun alanında öne veya arkaya doğru hareket etme ihtiyacı,

- Non-lokomotor beceriler (denge ve vücudun sabit kalması gibi) ile bedenini oynatabilme, döndürebilme ve tüm vücudu ile oyun ekranında en uygun pozisyonu alabilme ihtiyac1,

- El kullanımına yönelik beceriler ile kol ve bacaklarını kullanarak oyun içerisinde bazı objeleri kontrol edebilme ihtiyac1,

- Hareket farkındalığı ile fiziksel hareket alanını doğru kullanabilme, oyun içerisindeki nesnelerle etkileşime geçmek için fiziksel hareket alanında doğru pozisyonu alabilme ihtiyac1,

- Vücut farkındalığı ile oyundaki objelerle etkileşime geçmek için onlardan ne kadar uzak veya yakın olduğunu tahmin edebilme ihtiyacı,

- Görsel geribildirimleri gözlemleyebilme ve onlara yönelik planlama yapabilme ihtiyacı.

Fiziksel etkileşime sahip oyunlar Matematik ve Fen Bilimleri gibi temel alanlara ek olarak özellikle kendi doğaları ve sahip oldukları benzersiz özelliklerden dolayı Beden Eğitimi alanında da kullanılacak potansiyele sahiptirler. $\mathrm{Bu}$ sayede, oyuncuların hem hareket yeteneklerini geliştirmeleri hem de bir temel alan dersi için pratik yapmaları, eğitim ortamları için iyi bir çözüm olabilmektedir. Ancak bu oyunların geliştirilmesi esnasında dikkat edilmesi gereken çok sayıda değişken bulunmaktadır. Özellikle, kameranın oyun ortamına yerleşimi, oyunda ihtiyaç duyulan temel fiziksel vücut hareketlerinin belirlenmesi, bu hareketlerin zorluk seviyelerinin oyun süresi içerisinde dengeli olacak şekilde ayarlanmas1, oyuncuların fiziksel hareketler ile oyunu oynamaya çalıștıkları esnada hem oyun ortamından hem de fiziksel ortamdan kopmadan oyunu oynamaya devam edebilmesi bunlardan öne çıkan bazılarıdır. Yapılan araştırmalar, çocukların özellikle fare ve klavye kullanmadan bu tür fiziksel etkileşim yöntemi ile oyun oynamayı sevdiklerini ortaya koymaktadır [10-11]. Fiziksel etkileşimli bilgisayar oyunlarının nasıl en eğlenceli, fonksiyonel ve uygun vücut hareketlerini içerecek şekilde tasarlanması gereği araştırılması gereken kritik sorulardandır [5]. Bu çalışmada 4 farklı fiziksel etkileşimli bilgisayar oyununun tasarım aşamasında katılımcılardan geribildirimler alınmış, oyun tasarımında dikkat edilmesi gereken konular ortaya konulmaya çalışılmıştır. 


\section{YÖNTEM (METHOD)}

$\mathrm{Bu}$ çalışmada nitel veri toplama yöntemi kullanılmıştır. Çalışmadaki her bir katılımcı ile yarı yapılandırılmış mülakat yöntemi ile verilerin toplanması sağlanmıștır. Mülakat soruları Genel Konular, Eğitsel İçerik, Görsel Tasarım, Kamera Kullanımı ve Etkileşim olmak üzere 5 kategoride katılımcılara yöneltilmiştir.

Genel konular, katılımcıların fiziksel etkileşime sahip oyunlara olan bakış açılarını belirlemeyi ve bu tür oyunların eğitim amaçlı kullanımlarının potansiyellerini ortaya koymayı amaçlamaktadır. Eğitsel içerik, oyunlardaki eğitsel içeriğin uygunluğunun, faydasının ve oyun ortamında sunuluş yönteminin katılımcılar tarafından değerlendirilmesini amaçlamaktadır. Görsel tasarım, oyunlarda yer alan görsel bileşenlerin, renk seçiminin, avatar kullanımının ve katılımcılara verilen oyun içi yönergelerin tasarım ve anlaşılabilirliğinin değerlendirilmesini amaçlamaktadır. Bunun yanında, kullanılan seslerin, efektlerin ve animasyonların da katılımcılar tarafından değerlendirilmesini içermektedir. Kamera kullanımı fiziksel etkileşimli oyunların en temel bileşenlerinden birisidir. Dolayısıyla, katılımcıların kamera ekranının boyutu ve etkili kamera kullanımı gibi konularda görüssleri alınmıştır. Fiziksel etkileşimli oyunların getirdiği en büyük yeniliğin fare ve klavye kullanımı olmadan oyun ortamı ile etkileşime geçilmesi olduğu düşünüldüğünde, bu yeni etkileşim yönteminin katılımcılar tarafindan değerlendirilmesi önem kazanmaktadır. Etkileşim başlı̆̆ında ise kamera tabanlı gerçekleştirdikleri etkileşimin katılımcılar tarafından değerlendirilmesi amaçlanmıştır.

\subsection{Katılımcllar (Participants)}

Katılımcıların demografik bilgileri 14 sorudan oluşan bir anket ile alınmıştır. Demografik anket, 7-9 yaş arasındaki katılımcıların etkileşimli sosyal oyun ortamındaki akış deneyimlerinin araştırıldığı bir çalışmada [12] kullanılan ankettir. Fiziksel etkileşimli oyunun tasarım prensiplerini ortaya koymak amacıyla 10 katılımc1 (5 erkek, 5 kız) çalışmada yer almıştır. Katılımcılar 7-9 yaş arasına sahip Ankara'da özel bir okulda eğitim gören 2. sinif öğrencilerinden oluşmaktadır. Katılımcıların tamamının evlerinde bilgisayarlarının olduğu ve eğitsel oyunları gerek evlerinde, gerekse de okulda oynama alışkanlığına sahip oldukları belirlenmiştir. Erkek katılımcıların sadece 2 tanesinin daha önce fiziksel etkileşime dayalı oyunları oynama tecrübelerinin olduğu, buna karşın kız katılımcıların tamamının fiziksel etkileşime sahip oyunlar konusunda herhangi bir tecrübelerinin olmadığ 1 belirlenmiştir.

\subsection{Fiziksel Etkileşimli Oyunlar (Physically Interactive Games)}

Çalışma kapsamında 4 adet fiziksel etkileşime sahip oyun geliştirilmiştir. Oyunların 2 tanesi hareket kontrollü etkileşim tasarımına sahip iken, 2 oyun ise hareket yönlendirmeli etkileşim tasarımına sahiptir.

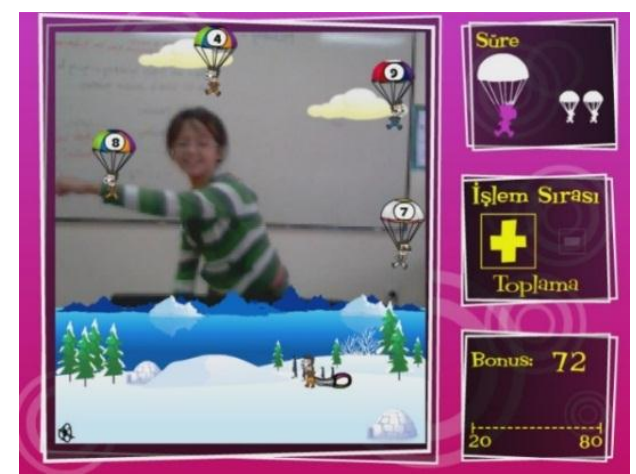

Şekill. Hareket kontrollü etkileşim tasarımına sahip oyun (Motion-controlled interactive game screen)

Hareket kontrollü etkileşim tasarımına sahip oyunlarda (Şekil 1) oyuncular oyun içerisindeki bileşenlerle ve nesnelerle doğrudan etkileşime geçebilmektedirler. Bunun için vücutlarının ya tamamını ya da bir uzuvlarını kullanmakta ve oyun içerisindeki nesnelere dokunarak onlarla etkileşimde bulunmaktadırlar. Hareket kontrollü etkileşime sahip oyunlarda kamera alanı oyun alanının büyük bölümünü kapsamakta ve oyundaki etkileşime geçilecek nesneler bu alan içerisinde yer almaktadır. Oyuncular kamera alanı içerisindeyken oyundaki nesnelerle etkileşim halinde olmaktadırlar. Dolayısıyla, bu tür oyunlarda kameranın etkin ve etkili kullanımı büyük önem kazanmaktadır.

Oyun esnasında kamera alanının dışına çıkılması veya oyunda kendilerine verilen ideal pozisyonun bozulmas1, oyuncuların oyun oynarken hata yapmalarına neden olabilecek temel gerekçelerdendir. Bu tür etkileşimli oyunlarda oyuncular oyun içerisinde kendilerinin avatarları olarak yer almaktadırlar. Gerçek dünyadaki fiziksel ortamda bulunurken, aynı zamanda sanal bir dünyanın avatarı olarak oyunu oynamaları bu tür etkileşimli oyunların en temel özelliklerindendir.

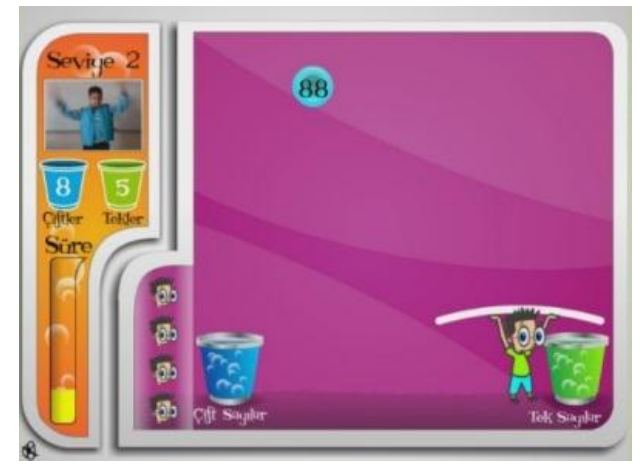

Şekil2. Hareket yönlendirmeli etkileşim tasarımına sahip oyun (Motion-driven interactive game screen)

Buna karşın, hareket yönlendirmeli etkileşim tasarımına sahip oyunlar (Şekil 2) oyuncuların oyun ortamını kamera aracılığıyla kontrol etmesi sağlamaktadırlar. Kamera ekranı oyun oynanma alanının dışında bir alanda yer almakta ve oyuncular kamera içerisindeki vücut hareketleri ile oyundaki nesnelerle etkileşime 
geçmektedirler. Bu tür etkileşime sahip oyunlarda kamera ekranı klasik oyunlardaki fare ve klavyenin işlevini görmekte, dolayısıyla katılımcıların kamera ekranını doğru kullanmaları büyük önem taşımaktadır.

Oyuncuların oyun alanı ile doğrudan etkileşime geçmediği hareket yönlendirmeli etkileşime sahip oyunlarda, oyuncuların rolü oyunun asli bir parçası olmak yerine, oyun ortamındaki nesneleri kontrol etmektir. Oyuncuların oyun ortamını doğru olarak yönetebilmesi için, kamera ekranı içerisinde kendilerinden beklenen fiziksel hareketlerin çok zor olmaması önemlidir. Diğer türlü, oyuncuların oyun ortamı ile kurduğu etkileşim sorunlu olacak, bu da oyundaki performanslarına olumsuz yansiyacaktır.

\subsection{Veri Toplama (Data Collection)}

Katılımcılarla gerçekleștirilen mülakatlar öncesi her katılımcı ortalama 20 dakikalık bir oturumda geliştirilen oyunları ayrı ayrı oynamıştır. Oyun oynama oturumundan sonra gerçekleştirilen mülakatlar her bir katılımcı için yaklaşık 15-20 dakika sürmüştür. Dolayısıyla, her bir katılımcı için veri toplama süresinin yaklaşık 35-40 dakika sürdüğü söylenebilir.

Mülakat esnasında not alma yöntemi kullanılmıştır. Katılımcıların geribildirimleri araştırmacı tarafından not alınmış, alınan notlar nitel veri analiz yöntemi ile değerlendirilmiştir. Mülakatlar okul içerisindeki boş bir sınıf kullanılarak gerçekleştirilmiştir. Tüm veri toplama süresi ise 2 hafta sürmüştür.

\section{BULGULAR (FINDINGS)}

Çalışmada elde edilen bulgular, mülakat konu başlıklarına göre değerlendirilmiştir. Buna göre genel konular dikkate alındığında, katılımcıların tamamının fiziksel etkileşimli oyunları oynamaktan büyük zevk aldığı belirlenmiştir.

\subsection{Eğitsel İçerik (Educational Content)}

Eğitsel içerik ile ilgili katılımcıların tamamı, oyunlarda sunulan içeriğin kendileri için uygun zorlukta olduğunu belirtmişlerdir. Katılımcıların geribildirimleri genel olarak Matematik dersine yönelik oyunda bulunan içerik ile ilgili olmuştur. Bir katılımc1, "Geometrik şekiller ve oyun içerisindeki hareket uygun. Oyunu vücudumla kontrol etmek beni şaşırttı. Oyunda fiziksel hareketler yaparken bir yandan da geometrik şekilleri toplamaya çalışmak faydalıydl." şeklinde belirtmiştir.

Katılımcıların motivasyonlarının yüksek olması oyunlardaki eğitsel içerikten daha fazla verim almalarını sağlamak için önemli bir etken olarak değerlendirilebilir. Örneğin bir katılımc1, "Daha önce de eğitsel oyunlar oynadım ve oynarken sikılmıştım. Bu oyunda yukarıdan aşağıya düşen numaralar var. Bunlar yere düşmeden aklımdan hesaplamam ve bir karar vermem gerekiyor. Sonra da numaralara dokunuyorum. Bu harikaydl." şeklinde görüş bildirmiştir.

\subsection{Kamera Kullanımı (Camera Use)}

Özellikle hareket kontrollü etkileşim tasarımına sahip oyunlarda, büyük kamera alanının olması katılımcılar tarafından daha fazla tercih edilmiştir. Özellikle kamera alanının büyük olduğu oyunlarda katılımcıların daha fazla eğlendiği ve oyun oynamayı istedikleri gözlemlenmiştir. $\mathrm{Bu}$ da hareket kontrollü etkileşim tasarımına sahip oyunların katılımcılar arasında daha fazla popüler olmasını sağlamıştır. Bir katılımcı, "Daha büyük kamera ekrant tercih ederdim. Oyunda kendimi kamerada görmek hoşuma gitti. Doğru hareketleri yapıp yapmadı̆̆ımı anlamak için büyük kamera olsa iyi olurdu. Bu sayede kendimi de kontrol ederdim." şeklinde görüş bildirmiştir.

Büyük kamera alanı kullanıldığı oyunlarda katılımcıların daha az hata yaptıkları ve kamera ekranı içerisindeki kendi pozisyonlarını daha kolay ayarladıkları görülmüştür. Bununla ilgili bir katılımc1, "Bu oyunu diğer oyunlardan daha çok sevdim. Oynaması çok kolaydı. Kamera ekranında kendimi kontrol etmem gerekmedi. Bazen bu zor oluyor, oyunda kendi görüntümü kaybedebiliyorum ama bu oyunda bunu kolayca düzeltebildim." şeklinde görüş bildirmiştir.

Kamera ekranının büyük tasarlandı̆̆ katılımcılar daha çok vücut hareketleri yapma imkânı bulmuşlardır. Örneğin bir katılımcı "Oyunda serbest hareketler yapmak eğlenceliydi. Bunu çok sevdim. Bu sayede tüm vücudumla oyun oynayabildim. Sağa veya sola yürüdüm, öne veya arkaya doğru adım attım." şeklinde görüşlerini belirtmiştir. Buna karşın, oyun içerisinde sabit olarak kalmak katılımcılar tarafından tercih edilmeyen vücut hareketlerinden birisi olarak belirlenmiştir. Katılımcılar vücutlarının sabit, sadece belli el veya ayak hareketlerinin olduğu oyunlar yerine tüm vücutlarını serbestçe hareket ettirebilecekleri oyunları daha fazla tercih etmişlerdir. Örneğin bir katılımcı, "Oyunda pratik yaparken sabit durmak biraz zordu. Benden doğru şekle tıklarken sabit kalmam ve sadece elimi, ayağımı veya kafamı kullanmam isteniyordu." şeklinde görüş bildirmiştir.

Katılımcıların oyun içerisinde daha az hata yapmalarını sağlamak için onlara daha fazla hareket alanı verilmesi ihtiyacı görülmüştür. Özellikle sabit olarak duran ve etraflarındaki nesnelere dokunmak isteyen katılımcılar yanlışlıkla istemedikleri nesnelere de dokunmak durumunda kalmışlar, bu da oyuna karşı olan motivasyonlarını azaltmıştır. Örneğin bir katılımcı, "Oyunda beni rahatsız eden tek şey alanımdl. Kameradaki duruşumu düzeltmek için daha fazla alanım olsun isterdim çünkü yanlışlıkla diğer şekillere de tıklayabildim. Ĕger daha fazla alan olsaydl, böyle hatalar yapmazdım." şeklinde görüş bildirmiştir. 
Hareket yönlendirmeli etkileşim tasarımına sahip oyunlarda kamera ekranını katılımcılar oyundaki nesneleri kontrol etmek için kullanmışlardır. Bazı katılımcıların bu tür oyunlarda özellikle zorlandıkları ve aynı anda hem kamera ekranına hem de oyun alanına odaklanmakta problem yaşadıkları belirlenmiştir. $\mathrm{Bu}$ sebeple, oyun oynama esnasında sıklıkla ideal pozisyonlarını kaybettikleri ve kamera alanının dışına çıktıkları görülmüştür. Bir katılımcı, "Daha önce klavye ve fare ile oynanan oyunlar oynamıştım. Çok kolaydl. Ama bu oyundaki kontrol çok farkl geldi bana. Oyundaki zorluk kamera ekranındaki doğru pozisyonumu sık sık unutmamdl." şeklinde görüş bildirmiştir. Dolayısıyla, oyun içerisinde belli periyotlarda oyunculara ideal kamera pozisyonlarının görsel olarak hatırlatılmasının önemli bir ihtiyaç olduğu görülmüştür.

\subsection{Görsel Tasarım (Visual Design)}

Katılımcılar oyunlarda kullanılan görsel tasarım nesnelerine yönelik olumsuz geribildiriminde bulunmamışlardır. Erkek katılımcılar özellikle oyunlardaki uçak gibi nesneleri daha fazla beğendiklerini ifade etmişlerdir. Bir katılımcı oyunlarda kullanılan animasyonlar ve ses efektleri ile ilgili olarak, "Animasyonları çok sevdim. Özellikle fabrika teması çok hoştu. Bütün animasyonlar iyiydi. Hareket ettiğim zaman duyduğum sesler de güzeldi. Doğru cevabı verdiğimde veya yanlış bir şekli bulduğumda farklı sesler vardl." şeklinde görüş bildirmiştir. Çalışma sonucunda, oyunlarda kullanılan arka plan müziklerinin, ses efektlerinin ve oyun ortamı ile etkileşim esnasında verilen sesli geribildirimlerin, katılımcıların oyuna karşı bakışlarını olumlu yönde etkilediği söylenebilir.

\subsection{Etkileşim (Interaction)}

Katılımcıların oyun boyunca motivasyonlarının yüksek olduğu görülmüştür. Katılımcıların kamera ekranını kullanarak kurmuş oldukları etkileşimin, yenilik etkisi ile motivasyonlarını önemli ölçüde arttırdığı söylenebilir. Örneğin, bir katılımc1 “Vücut hareketleri yapmak oyunu çok cazip hale getiriyor. Doğruyu söylemek gerekirse, bu oyunu fare ve klavye ile oynamak istemem. Oyun oynarken böyle hareketler yapmak bu oyunu oynatıyor çünkü çok zevkli." şeklinde görüş belirtmiştir.

K1z katılımcıların hareket kontrollü etkileşime sahip oyunları özellikle arkadaşları ile aynı anda oynamayı tercih ettikleri belirlenmiştir. Oyun içerisinde kamera ekranında kendi arkadaşları ile aynı anda oynayacakları oyunun kendileri için daha eğlenceli olacağından bahsetmişlerdir. Örneğin, "Ĕger bu oyunu bir arkadaşımla aynı anda oynayabilseydim daha ĕglenceli olurdu. Oyundaki karakteri birlikte kontrol ederdik. Belki ben onu sola doğru hareket ettirirdim, arkadaşım da să̆a doğru." şeklinde görüş bildirmiştir.

\subsection{Oyun Bileșenleri (Game Components)}

Oyun içerisinde kendilerinden yapmaları beklenen fiziksel hareketleri yaparken katılımcilar zorlanmamışlardır. Özellikle erkek katılımcılar oyunun daha uzun süreli olmasını tercih etmişlerdir. Bir erkek katılımc1, "Oyunu çok sevdim ancak seviyeler daha uzun olmal. Oyun çok eğlenceliydi. Bitmesini hiç istemedim. Sadece her seviyede daha uzun süreli olmasını isterdim." şeklinde görüş bildirmiştir. Ancak bazı katılımcıların oyun sonlarına doğru yorulduğu gözlemlenmiştir. K1z katılımcıların bu konuda erkek katılımcılara göre daha hassas olduğu görülmüştür. Kız katılımcıların büyük bölümü oyunu oynadıktan sonra özellikle süresi konusunda geribildirim verme ihtiyacı duymuşlardır. Örneğin bir katılımc1, "Oyunda 4 hakkın olması benim için uygun. Aslında oyunda çok daha fazla seviye olsun isterim, ancak bu zaman da hareketleri yaparken çok yorulabiliriz. Bu yüzden oyunda düşen topların hızı için 3 seviyeli olması uygun gibi." şeklinde görüş belirtmiştir. $\mathrm{Bu}$ tür fiziksel gereksinimlerle oynanan oyunlardaki oyun oynama sürelerinin dikkat edilmesi gereken konuların başında geldiğinin önemli bir göstergesidir.

Katılımcıların tamamına yakınının fiziksel etkileşimli oyunlar ile ilgili bir deneyimleri olmadığından dolayı, bazı katılımciların oyunun oynanma yapısını anlamasının zor olduğu görülmüştür. Özellikle kız katılımcıların erkek katılımcılara göre oyuna adapte olmakta zorlandı̆̆ gözlemlenmiştir. Örneğin bir katılımc1, "Oyuna başlamadan önce nasıl oynayacağımı anlamamıştım. Insana benzeyen birinin oyunu nasıl oynayacağımızı göstermesi iyi oldu. Onun yaptı̆̆ hareketlerin aynısını yapmaya çalıştım ben de." şeklinde görüş bildirmiştir. Dolayısıyla, oyun öncesinde, oyuncuların oyunu nasıl oynayacağının simülasyonunun hazırlanmasının ve ihtiyaç duyduklarında izleyebilmelerinin sağlanmasının önemli olduğu görülmüştür.

\section{TARTIŞMA VE SONUÇ (DISCUSSION AND CONCLUSION)}

Fiziksel etkileşime dayanan bilgisayar oyunları son yıllarda ortaya çıkan yeni bir oyun türüdür. Klasik oyunlardaki gibi fare veya klavye kullanılarak oynanmadıklarından dolayı, bu oyunların tasarımlarında dikkat edilmesi gereken konular oldukça farklılık göstermektedir. Özellikle kamera kullanımının fiziksel etkileşimli oyunlarda oyunun temel bileşeni olması ve oyuncuların oyun ortamı ile doğrudan veya dolaylı olarak etkileşime geçmeleri için önemli bir görev üstlenmesi, bu tür oyunların tasarımlarında bazı prensiplerin ortaya konulması ihtiyacını ortaya koymaktadır.

$\mathrm{Bu}$ çalışmada 4 farklı fiziksel etkileşimli bilgisayar oyununun tasarımı aşamasında katılımcılardan geribildirimler alınmış, oyun tasarımında dikkat edilmesi gereken konular ortaya konulmaya çalışılmıştır. Geliştirilen oyunlardan 2 tanesi hareket kontrollü etkileşim tasarımına sahip iken, diğer 2 oyun ise hareket yönlendirmeli etkileşim tasarımına sahiptir. 
Çalışma sonucunda fiziksel etkileşime dayanan bilgisayar oyunlarının tasarımlarında aşağıdaki konuların dikkat edilmesi gereği ortaya çıkmaktadır;

- Fiziksel etkileşimli oyunlarını oynanabilmesi için vücut hareketleri temel gereksinimdir. Ancak bu tür oyunların tasarımında oyunculara sadece fiziksel egzersiz yaptırmak yerine, beraberinde farklı bir alanda da pratik yaptırabilecek oyun kurgusu geliştirmek önemli fayda sağlayacaktır.

- Büyük kamera alanı kullanımı katılımcıların motivasyonunu yükseltmekte ve oyuna karşı daha fazla ilgisini çekmektedir.

- Büyük kamera alanında katılımcıların daha az hata yaptıkları ve oyuna daha fazla konsantre oldukları gözlemlenmiştir.

- Oyun esnasinda oyunculara kisitlı hareket alanı sunmak, onların hata yapmalarına neden olmakta ve oyundaki motivasyonlarını düşürmektedir. Dolayısıyla oyuncuların oyun içerisinde serbest hareket alanlarının bulunması önemlidir.

- Oyun kurgusunda oyuncuların uzun süre sabit kalmasını gerektirecek bir tasarımdan uzak durulmalidir.

- Kamera ekranının oyundaki nesneleri kontrol etmek için kullanıldığı durumlarda, kamera alanı oyunun ana alanına yakın tasarlanmalıdır. Diğer türlü oyuncuların hem kamera alanına hem de oyunun ana alanına aynı anda odaklanmada zorlandıkları ve dikkatlerinin sıklıkla dağıldığ görülmüştür.

- Oyun öncesinde oyunculara oyunda hangi fiziksel hareketlerin kendilerinden beklenildiğini animasyonla anlatılması önemlidir.

- Oyun esnasında özellikle kamera ekranı içerisindeki ideal kamera pozisyonu kaybeden oyuncular için belli periyotlarda ideal kamera pozisyonu görsel anlatım ile hatırlatılmalıdır.

- Oyun içerisinde arka plan müziği, ses efektleri ve oyuncuların oyundaki etkileşimlerine yönelik ses ile geribildirimler verilmesi önemlidir.

- Fiziksel etkileşimli oyunları kız katılımcıların arkadaşları ile oynamayı daha fazla tercih ettikleri görülmüştür. Dolayısıyla, isteyen oyuncular için oyunların 2 oyuncunun aynı anda oynayabileceği kurgu ve tasarımda geliştirilmesi önemlidir.

- Özelikle kız katılımcılar kendilerinden beklenen fiziksel hareketleri yaparken oyun sonlarına doğru yorgunluk belirtileri göstermişlerdir. Dolayısıyla, oyunların sürelerinin buna göre ayarlanması ve oyunları oyuncuların istedikleri zaman durdurabilmeleri sağlanmalıdır.
Fiziksel etkileşime dayanan oyunlara karşı son yıllarda oyuncuların ilgisi daha da artmaktadır. Ancak bu oyunların sahip oldukları özellikler, klasik oyunlar ile aynı tasarım ilkelerine göre geliştirilmelerinin mümkün olmadığını göstermektedir. Fiziksel etkileşimli oyunların hedef kitle için en uygun, etkili ve verimli tasarım ve geliştirme süreçlerine sahip olması için yeni çalışmalara ihtiyaç duyulmaktadır. Bu çalışmada ortaya konulan bulguların, ilerleyen zamanlarda daha geniş kitle ve farklı oyun kurguları ile yapılacak yeni çalışmalar için yol gösterici olması amaçlanmıştır.

\section{KAYNAKLAR (REFERENCES)}

[1] C. Bauckhage, C. Thurau, "Exploiting the Fascination: Video Games in Machine Learning Research and Education". 2nd International Workshop in Computer Game Design and Technology, Liverpool, UK, 2004 .

[2] Y. Inal, K. Cagiltay, "İlköğretim Öğrencilerinin Bilgisayar Oyunu Oynama Alışkanlıkları ve Oyun Tercihlerini Etkileyen Faktörler". Eğitimde Yeni Yönelimler II Eğitimde Oyun Sempozyumu, Ankara, 2005 .

[3] K.M. Inkpen, K.S. Booth, M. Klawe, "Drag-and-Drop Versus Pointand-Click Mouse Interaction Styles for Children". ACM Transactions on Computer-Human Interaction, 8(1), 1-33, 2001

[4] J. Höysniemi, P. Hamalainen, L. Turkki, "Using Peer Tutoring in Evaluating the Usability of a Physically Interactive Computer Game with Children". Interacting with Computers, 15, 203-225, 2003.

[5] J. Höysniemi, Design and Evaluation of Physically Interactive Games. Doktora Tezi, University of Tampere, Tampere, Finland, 2006.

[6] M. Bekker, E. van den Hoven, P. Peters, B.K. Hemmink, "Stimulating Children's Physically Play Through Interactive Games: Two Exploratory Case Studies". 6th International Conference on Interaction Design and Children, Aalborg, Denmark, 2007.

[7] M. Kostomaj, B. Boh, "Evaluation of User's Physical Experience in Full Body Interactive Games". 4th International Conference on Haptic and Audio Interaction Design, Dresden, Germany, 2009.

[8] S.J. Lu, P.L. Fan, Y.C. Liu, Y.C. Chuang, "Design and Evaluation of Physically Interactive Games for Taiwanese Local Dialect in Elementary School Teaching". 2nd International Conference on Education Technology and Computer, Shanghai, China, 2010

[9] J. Höysniemi, P. Hamalainen, L. Turkki, T. Rouvi, "Children's Intuitive Gestures in Vision-Based Action Games". Communications of ACM, 48(1), 44-50, 2005.

[10] J. Höysniemi, P. Hamalainen, “Children's and Parents' Perception of Full-Body Interaction and Violence in a Martial Arts Game". International Conference on Designing for User eXperience, New York, USA, 2005

[11] J. Höysniemi, A. Aula, P. Auvinen, J. Hannikainen, P. Hamalainen, "Shadow Boxer - a Physically Interactive Fitness Game". NordiCHI Conference, Tampere, Finland, 2004.

[12] Y. Inal, K. Cagiltay, "Flow Experiences of Children in an Interactive Social Game Environment”. British Journal of Educational Technology, 38(3), 455-464, 2007. 